\title{
STATUS OF Penaeus monodon FARMS, DEPOTS AND PROCESSING INDUSTRIES OF SOME SELECTED AREAS OF BANGLADESH
}

\author{
M. Faridullah, M. N. Haider, M. Kamal and M. N. Islam \\ Department of Fisheries Technology, Bangladesh Agricultural University \\ Mymensingh-2202, Bangladesh
}

\begin{abstract}
A survey was carried out to evaluate the overall condition, infrastructure facilities, handling and quality management system, condition of raw materials of shrimp, Bagda (Penaeus monodon) farms and depots of some selected shrimp producing areas of Cox's Bazar (Chokoria and Teknaf), Khulna (Paikgacha and Koira), Bagerhat (Rampal and Mongla) and Satkhira (Munshiganj and Ashashuni) through direct observation and interview with cross section of people engaged in farms, depots and processing industries. The survey results revealed that the production of shrimp was not satisfactory. The post-harvest quantitative and qualitative losses in the farms were due to longer duration of harvesting, exposure of shrimp at high ambient temperature for a long time (delayed icing), contamination from dirty floor and lack of general hygiene and sanitation. On the other hand, major quality loss in depots were due to delayed icing, use of inadequate ice, rough handling and peeling, presence of foreign materials, packed under pressure in the bamboo basket, contamination, body crushing, use of dirty utensils and lack or poor personal hygiene of depot workers.
\end{abstract}

Key words : Penaeus monodon, Farms, Depots, Industries

\section{INTRODUCTION}

The overall shrimp quality management system of our country is not satisfactory. Shrimp are usually subjected to the contamination and spoilage due to improper handling, unhygienic care, inadequate facilities of transportation, processing, refrigeration, storage and distribution. Shrimp are more perishable food items than any other foodstuffs and there quality is dependent on a number of factors including harvest condition, handling and storage time and temperature. In the country, most of the shrimp farmers, and handlers are not conscious about the post-harvest handling. Processing industries purchase most of their raw materials through a number of channels and post-harvest losses occur at different stages of handling and transportation. It normally takes $24-48 \mathrm{hr}$ to transport the raw materials from farm to the processing plants. The effect of delayed post-harvest handling exerts serious threat on quality of $P$. monodon and $M$. rosenbergii (Reilly et. al., 1985; Rahman et. al., 2001a, 2001b, 2001c) which clearly indicate that exposure of raw material at high temperature for a longer period in tropical climate drastically reduce the shelf life of shrimp and prawn. 
Exportable shrimp requires special care to keep its original physical appearance, odor and organoleptic characteristics as much as possible. It must be free from dirt, filth, pathogenic organisms, uncertified chemicals and any antibiotics even in the minutest quantity. The importing countries particularly, the EU countries, USA and Japan are highly conscious about food hygiene and safety.

The present status of quality management system of shrimp at farms, and depots lead to losses of shrimp both in quality and quantity, which in turn lead to substantial economic loss. However, any loss of this very valuable exportable resource is most undesirable. Reliable information to quantify such losses at various points of shrimp handling is lacking. At this point of time when the nation is struggling to enhance export, it is very important that the quantitative and qualitative losses of shrimp in its value chain from farm to factory be quickly assessed, measures to avert the losses be prescribed, policy to salvage the resource be formulated and the recommended measures be enforced for the sake of national interest.

\section{MATERIALS AND METHODS}

Information on the infrastructure facilities and qualitative and quantitative losses of shrimp at various stages of handling and transportation were collected from the farms, depots and processing industries of four prominent Bagda producing districts Cox, $\mathrm{s}$ Bazar, Satkhira, Khulna and Bagerhat through direct observation and interview with cross section of people using prescribed questionnaires. The questionnaires were developed jointly by Department of Fisheries Technology, Bangladesh Agricultural University, Mymensingh and Bangladesh Shrimp Foundation, Dhaka. From each district two upazila were selected and from each upazila two farmers and two depot owners were randomly selected for sampling. Thus, 16 farmers and 16 depot owners were selected from 8 upazila of 4 districts to collect the information (table 1).

Table 1. Nomber of farmers and depot owners from four districts of Bangladesh

\begin{tabular}{llc|c}
\hline \multicolumn{1}{c|}{ Districts } & \multicolumn{1}{c|}{ Upazila } & No. of farmers & No. of depot owners \\
\hline Cox's Bazar & Teknaf & 2 & 2 \\
& Chakoria & 2 & 2 \\
Satkhira & Munshiganj & 2 & 2 \\
& Kaliganj & 2 & 2 \\
\multirow{3}{*}{ Khulna } & Koira & 2 & 2 \\
& Paikgacha & 2 & 2 \\
\multirow{5}{*}{ Bagerhat } & Mongla & 2 & 2 \\
& Rampal & 2 & 2 \\
\hline
\end{tabular}

Information was also collected from four processing industries of two districts. Kuliarchar Fish Processing Industry and Conception Seafood Processing Industry of Cox's Bazar and Rupsha Fish and Allied Indusry and Fresh Seafood Industry of Khulna. 


\section{RESULTS AND DISCUSSION}

\section{Condition of Bagda farms of Bangladesh}

To assess the condition of Bagda farms, some important aspects were taken into consideration such as sources of water and drainage system, latrine on the farms, removal of pond scum, water quality parameters ( $\mathrm{pH}$, depth, secchidisc reading, mortality) etc.

Table 2. General condition of Bagda farms of Bangladesh

\begin{tabular}{l|l}
\hline \multicolumn{1}{c|}{ Major aspects } & \multicolumn{1}{c}{ Present status } \\
\hline $\begin{array}{l}\text { Water received from or drain out to } \\
\text { another farms }\end{array}$ & $\begin{array}{l}\text { 60\% farms receive from or drain out to } \\
\text { another farms }\end{array}$ \\
Latrine on the farms & No \\
Removal of pond scum & No \\
Water source & Use tidal water \\
Water quality monitoring & - Not monitored \\
- pH & $-3-4 \mathrm{ft}$ \\
- Depth & - No \\
- Secchidisc reading & $-10-20 \%$ due to disease \\
\hline
\end{tabular}

About $60 \%$ farms were found to receive water from other ponds and drain out water to yet other ponds in all survey areas. There was a little or no evidence of using cowdung or chicken manure in Bagda farms. No make-shift or permanent latrines constructed on the Bagda farms. Pond scum are not removed in any Bagda farms. The main water source for Bagda farms was tidal water during high tide. The average depth of Bagda farms in all study areas were in the range of 3-4 ft. Mortality of shrimp due to white spot and other diseases is common in all Bagda farms. The farmers reported that $10-20 \%$ shrimp are lost due to diseases. The Bagda farmers do not monitor water quality of their farms (Table 2).

\section{Infrastructure facilities of Bagda farms}

The major infrastructure facilities considered in the study were shade for keeping the harvested shrimp, temporary holding containers, basket type, ice storage facilities, ice crushing box etc. Only $12 \%$ farms have been found built shade for keeping the harvested shrimp. Bamboo basket, plastic sheet, plastic drum and cemented floor were used for temporary holding of Bagda. The shrimp holding baskets used in the farms were $90 \%$ bamboo made and $10 \%$ plastic containers. There was no ice storage facility and icecrushing box in Bagda farms (Table 3).

Production, post-harvest care and transportation and in Bagda farms Bagda were harvested at night during high tide of the lunar cycle by using both cast net and traps. The duration between the start of harvesting to marketing of Bagda was about 5-8 hrs. The 
production of shrimp and finfish from Bagda farms were 370-620 kg/ha for Bagda, 75-500 $\mathrm{kg} / \mathrm{ha}$ for Horina and $125-370 \mathrm{~kg} / \mathrm{ha}$ for finfish.

Table 3. Infrastructure facilities of Bagda farms

\begin{tabular}{l|l}
\hline \multicolumn{1}{c|}{ Major aspects } & \multicolumn{1}{c}{ Present status } \\
\hline Shade for keeping the harvested shrimp & $\begin{array}{l}\text { Only 12\% farms have shade } \\
78 \% \text { use bamboo basket, 12\% plastic sheet, 10\% } \\
\text { Temporary holding of shrimp }\end{array}$ \\
& $\begin{array}{l}\text { cemented floor } \\
90 \% \text { bamboo made, 10\% plastic drums }\end{array}$ \\
Basket type & No \\
Ice storage facilities & No \\
Ice crushing box &
\end{tabular}

Table 4. Production, post-harvest care and transportation and in Bagda farms

\begin{tabular}{|c|c|}
\hline Major aspects & Present status \\
\hline Harvesting time & $100 \%$ at night during high tide (lunar cycle) \\
\hline Harvesting method & $60 \%$ cast net, $40 \%$ traps \\
\hline Duration between start of harvesting to marketing & $5-8 \mathrm{hrs}$ \\
\hline Farm production $(\mathrm{kg} / \mathrm{ha})$ & $\begin{array}{l}\text { Bagda-370-620, Horina-75-500, } \\
\text { Fin fish-125-370 }\end{array}$ \\
\hline Initial washing after harvest & $80 \%$ with pond water, $20 \%$ tube well water \\
\hline Sorting and grading & No sorting and grading \\
\hline Shrimp head removal & No \\
\hline Ice used & No \\
\hline Basket washing & $100 \%$ washed regularly \\
\hline Mat washing & $100 \%$ washed regularly \\
\hline Detergent used & No \\
\hline Distance from farm to depot $(\mathrm{km})$ & $1-4$ \\
\hline Transportation container & $60 \%$ use bamboo basket and $40 \%$ plastic \\
\hline Transportation from farm to depot & $60 \%$ manually, $30 \%$ rickshaw, $10 \%$ van \\
\hline
\end{tabular}

The post-harvest care of Bagda considered in this study area were initial washing after harvesting, sorting, grading, beheading and icing of Bagda and overall cleanliness and sanitation of equipment and utensils used in farms. About $80 \%$ farmers used pond water for initial washing of shrimp after harvest. The farmers usually do not practice sorting and grading of Bagda before transporting to the depots and industry.

The farmers did not practice beheading and icing at farm level. Basket and mat washing were done regularly at farm levels but they did not use any type of detergent for washing. The farmers supplied shrimp to the depots after harvesting and the distance 
from farm to depot was $1-4 \mathrm{~km}$. About $60 \%$ farmers used bamboo basket and $40 \%$ farmers used plastic drum for transportation of shrimp. About $60 \%$ Bagda were transported by the farmers manually, $30 \%$ by rickshaw and $10 \%$ by van (Table 4 ).

\section{Infrastructure facilities of Bagda depots}

The considered infrastructure facilities in the Bagda depots of Cox`s Bazar, Satkhira, Khulna and Bagerhat regions included were- roof, ceiling, walls, floors, windows, doors, stainless steel table, animal control fencing, ice plant, ice storage, sanitary latrine, drainage, electricity, water source and foot dip. The roofs of the $76 \%$ depots were made of tin, $16 \%$ were of concrete and the rest were made of straw and leaf. Some depots $(8 \%)$ in Teknaf region also used straw as roof of the depots. About $80 \%$ of the Bagda depots had the walls constructed with bricks and $20 \%$ with tin. The floors of the $99 \%$ depots were constructed with cement and in 1\% depot's floor was of mosaic. About 96\% Bagda depots had no fly net in their doors and windows. About $85 \%$ depots had stainless steel table for sorting of raw materials but in most cases not in good condition. All the Bagda depots had animal control fencing. There was no ice plant but ice storage facilities were available in the study areas. About $90 \%$ depots had sanitary latrine. There was a drainage system in all depots but the condition was very poor. Electricity and tube well water were available in all the depots. There were no foot dip facilities at all in any Bagda depots except one in Chakaria, Cox's Bazar (Table 5).

Table 5. Infrastructure facilities of Bagda depots

\begin{tabular}{l|l}
\hline \multicolumn{1}{c|}{ Major aspects } & \multicolumn{1}{c}{ Observation } \\
\hline Roof & $76 \%$ tin, 16\% concrete, $8 \%$ straw \\
Ceiling & $76 \%$ tin, 16\% concrete, $8 \%$ straw \\
Walls & $80 \%$ bricks, 20\% tin \\
Floor & $99 \%$ cemented and 1\% mosaic \\
Windows & $96 \%$ no net, $4 \%$ net \\
Doors & $96 \%$ no net, $4 \%$ net \\
Stainless steel table & $85 \%$ has table but in no use, 15\% has no table \\
Animal control fencing & $100 \%$ has fencing \\
Ice plant & No \\
Ice storage & Yes \\
Sanitary latrine & $90 \%$ has no sanitary latrine \\
Drainage & Yes \\
Electricity & Yes \\
Water source & Tube well \\
Foot dip & $99 \%$ has no foot dip, less than $\%$ has foot dip \\
\hline
\end{tabular}




\section{Condition of Bagda during receiving at depots}

The major considered aspects in the study were container type, icing, head removal, grading, transport, distance between farms and depots, total quantity of shrimp and prawn received (previous year), total quantity of ice used (previous year), and cost of ice. About $60 \%$ bamboo baskets and $40 \%$ plastic drums are used in depots. In depots, $90 \%$ raw materials are received without iced condition. About 100\% Bagda is received without grading. Rickshaw, rickshaw van and boat are also used for transportation of Bagda. The distance between farm and depot is in the range of $1-20 \mathrm{~km}$. The total Bagda received last year varied from 2-1100 ton by an individual depot. The price of ice varied from TK.1.50-2.00/per kg depending on demand and availability of ice (Table 6).

Table 6. General condition of Bagda during receiving at depots

\begin{tabular}{l|l}
\hline \multicolumn{1}{c|}{ Major aspects } & \multicolumn{1}{c}{ Present status } \\
\hline Container type & $60 \%$ bamboo basket, 40\% plastic drum \\
Icing & $90 \%$ not in iced condition, 10\% iced condition \\
Head & Head on \\
Grading & $100 \%$ non graded \\
Transport & $47 \%$ van, $40 \%$ rickshaw, $7 \%$ boat, $6 \%$ man \\
Distance between farm and depot & $1-20 \mathrm{~km}$ \\
Total quantity (last year) & $2-1100 \mathrm{ton}$ \\
Ice quantity(last year) & $2-1200 \mathrm{ton}$ \\
Ice cost & Tk. $2 / \mathrm{kg}$ \\
\hline
\end{tabular}

\section{Handling and transportation of Bagda at depots}

At depots, beheading and size grading of shrimp were not practiced but rejection of Bagda $(<1 \%)$ was happened due to peeling. Usually after receiving, Bagda were washed with tube well water and preserved in ice (ice-shrimp ratio 1:1). Before transporting the Bagda were packed in plastic drum covered by polythene sheet. Before transporting the raw materials to the factory maximum holding time of Bagda at depot was 2-10 hrs. The distance from depots to factory varied from $20-200 \mathrm{~km}$ and required 1-4 hrs to reach at factory. The waiting time for delivery of Bagda to the factory was about 1-2 hrs. Lifebuoy soap, bleaching powder, detol, savlon etc. were used for personal washing, washing of floor, basket, mats, weighing machine etc. in the depots (Table 7).

Comparison between depot owners' opinions interviewers' observation about the losses of shrimp during previous year

According to depot owners, less than 1\% Bagda received from suppliers/farmers was spongy. The quantity rejected due to discolouration was $1-2 \%$ and body crushing was $0.5-1 \%$. Less than $1 \%$ raw materials was found to contain water in their body. The depot owners reported that there was no Bagda with foreign materials, dirts and mud during 
receiving at depots. The total amount of discarded shrimp due to the above mentioned causes was about $1-2 \%$.

On the other hand, the interviewers found quality defect of Bagda as a result of spongy texture was less than $1 \%$, discoloration $1-3 \%$, body crushed $1-2 \%$, with excess water $1-2 \%$, with foreign materials less than $1 \%$, with dart and mud less than $1 \%$ and unfit for export $<1 \%$. The workers cleanliness and overall knowledge about post harvest quality management of Bagda at depot may be considered as poor to moderately good (Table 8).

Table 7. Handling and transportation of Bagda at depots

\begin{tabular}{l|l}
\hline \multicolumn{1}{c|}{ Major aspects } & \multicolumn{1}{c}{ Present status } \\
\hline Head removal & No \\
Peeling & Less than 1\% \\
Size grading & No \\
Washing & Yes \\
Icing and ice ratio & Use ice in the ratio of 1:1 \\
Packaging & Plastic drum with polythene \\
Maximum holding time & $2-10$ hours \\
Container & $100 \%$ plastic \\
Distance from factory & $20-200 \mathrm{~km}$ \\
Time to reach at factory & $1-4 \mathrm{hrs}$ \\
Waiting time for delivery & $1-12 \mathrm{hrs}$ \\
\hline
\end{tabular}

Table 8. Comparison between depot owners' opinions interviewers' observation about the losses of shrimp for the year of 2003

\begin{tabular}{l|c|c}
\hline \multicolumn{1}{c|}{ Major aspects } & Depot owners' opinions & Interviewers' observation \\
\hline Spongy & Less than $1 \%$ & Less than $1 \%$ \\
Discoloration & $1-2 \%$ & $1-3 \%$ \\
Body crushes & $0.5-1 \%$ & $1-2 \%$ \\
With excess water & Less than $1 \%$ & $1-2 \%$ \\
With foreign materials & $0 \%$ & Less than $1 \%$ \\
With dirt and mud & $0 \%$ & Less than $1 \%$ \\
Discarded & $1-2 \%$ & $1-3 \%$ \\
Workers cleanliness & - & $80 \%$ poor, $20 \%$ fair \\
Workers knowledge & - & $90 \%$ poor, $10 \%$ fair \\
Depots cleanliness & - & $87 \%$ poor, $13 \%$ fair \\
\hline
\end{tabular}




\section{Factory managers opinion about the shrimp quality for the year of 2003}

According to factory managers, use of bamboo baskets as containers for shrimp was none, while $100 \%$ plastic baskets were used to carry the shrimp at receiving point. Core temperature of shrimp above $5^{\circ} \mathrm{C}$ at receiving point was $1-5 \%$ while core temperature above $10^{\circ} \mathrm{C}$ was none. The quality defect due to spongy texture was $1 \%$ and discoloration was below $1 \%$. There was no report of body crushing and contamination with foreign materials, dirt and mud during receiving in the industry. The shrimp received with excess water was only less than $1 \%$. The total discarded amount due to all types of defects was only $1-2 \%$. According to the factory managers, temperature was recorded at different stages of processing. For the storage of un-processed shrimp there were chill rooms in all the processing industries. All the factory managers were agreed that receiving of shrimp at high temperature was most important factor for the growth of Salmonella (Table 9).

Table 9. Factory manager's opinion about the shrimp quality for the year of 2003

\begin{tabular}{l|l}
\hline \multicolumn{1}{c|}{ Quality aspects } & \multicolumn{1}{c}{ Bagda factory } \\
\hline Shrimp receiving point : & \\
- Shrimp in bamboo basket & $-0 \%$ \\
- In plastic basket & $-100 \%$ \\
- With core temperature above $5^{\circ} \mathrm{C}$ & $-1-5 \%$ \\
- With core temperature above $10^{\circ} \mathrm{C}$ & $-0 \%$ \\
- Spongy & $-1 \%$ \\
- Discoloration & - Less than $1 \%$ \\
- Body crushed & $-0 \%$ \\
- With excess water & - Less than $1 \%$ \\
- With foreign materials, dirt, mud & $-0 \%$ \\
- Discarded from all & - Less than $1-2 \%$ \\
Temperature recording at different stages of processing & Yes \\
Non-processed shrimp storage room & Chill room \\
Panning room & Yes \\
Points most vulnerable to Salmonella growth & Receiving of shrimp at high temperature \\
\hline
\end{tabular}

The quality of finished products depends on the quality of raw materials. Therefore, to produce good quality shrimp and shrimp products, the raw shrimp should be wholesome. Moreover, the wholesomeness of finished products depends on the harvesting, post-harvest care, transportation, handling and sanitation and hygiene aspects at farms, depots and industry levels. In view of the above points, it can be said that the overall condition of Bagda farms in all the survey areas regarding infrastructure facilities, harvesting and production, post-harvest care and transpiration are not so satisfactory. Mazid et al. (2001) studied the production, processing, transportation and handling of shrimp at farm level and reported that the overall management procedures of 
the farms in respect of drying the pond bottom, ploughing, liming, fertilization, feeding, post harvest handling, transportation and marketing system are very poor. It has been also reported that shrimp being a perishable item, its quality is depended on many factors including harvesting condition, handling and storage time and temperature. In the present study, it was found that most of the farms are lack of ice storage facilities and shrimp are left at the farm site for about 5-8 hours without ice. In addition, most of the farmers $(90 \%)$ have no knowledge about the quality of shrimp. As a result, shrimp gradually lose their freshness, contaminated with microbes and become deteriorated. In every study area at farm level, it is observed that shrimps were mainly transported to depots manually and by rickshaw and van under unsanitary condition, and shrimp were subjected to excessive pressure and rough handling.

Most of the depots of the study areas were not properly equipped or not provided with adequate facilities for shrimp handling. The overall sanitary conditions were also poor. In most cases, there was no ice supply facility in depots. The facilities for temporary preservation were also unsatisfactory. Most of the depots had proper roof, ceiling, wall and floor. The depots were also with drainage system but there was no drainage covering grids in most cases. The information about the depots also revealed that the serious threat to the quality of shrimp may come from inadequate infrastructure facilities which can facilitate the microbial contamination of piled shrimp. Deterioration of shrimp quality in the depots was caused by microorganism (Fatima et al., 1988; Cheng and Lain, 1979). Personnel hygiene and sanitation as a whole in the depots of the study areas were not satisfactory. Many hygienic problems may arise from depot personnel/staffs themselves. In most cases, shrimp handlers were not aware about the importance of personnel hygiene. Depot operators or owners were not conscious about modern technologies for handling operation. Many of the depots were not given priority to the improvement of sanitary condition. Moreover, most of the depots in the study areas were found to have no door or window screens facilities against flies, cockroaches, insects etc. and rats were also found to move around. Since the shrimp handler/operators of the depots were mostly illiterate, indifferent, they take little interest in maintaining good sanitation and hygiene. None of the depots were found to use chlorinated water for foot dip or washing. Water was the chief vehicle through which diseases are transmitted. Therefore, adequate supply of good quality water for cleaning purposes must be ensured in the depots. At the depots shrimps were held until bulk amount of shrimps were collected before transported to the factory. Shrimps were transported to the factory mostly in plastic container. However, shrimps often packed under pressure cause physical damage (Hussain and Uddin, 1995). Lack of sufficient ice, improper handling and lack of suitable transport facilities in time were responsible for considerable loss of shrimp both in quality and quantity.

\section{REFERENCES}

Cheng, C.Y. and Lain, J. L. 1979. Studies on the decomposition of frozen shrimp II. Deterioration during iced and refrigerated storage. Nat. Sci. Council Monthly (R.O.C) 7: 1136. 
Fatima, R., Khan, M. A., Qadri, R. B. 1988. Shelf-life of shrimp (Penaeus merguiensis) stored in ice $\left(0^{\circ} \mathrm{C}\right)$ and partially frozen $\left(-3^{\circ} \mathrm{C}\right)$. J. Food Sci. Agric., 42: 235.

Hussain, M. M. and Uddin, M. H. 1995. Quality control of marketing of fish products: Needs of infrastructure and legal support. Paper presented in the national workshop on Fisheries resources, Development and management, held on 29 October to 01 November, Dhaka, Bangladesh.

Mazid, M. A., Ahmed, S. U., Kamal, M. and Ialam, M. N. 2001. Bangladesh Agricultural Research Council (BARC) Completion report on project "Studies on the Improved Production, Processing, Transport and Handling of Shrimp and Their Cost Benefits at Farm Levels". Bangladesh Fisheries Research Institute (BFRI) and Department of Fisheries Technology, Bangladesh Agricultural University, Mymensingh.

Rahman, M., Yasmin, L., Kamal, M., Islam, M. N. and Ochiai, Y. 2001a. Quality changes in freshwater prawn Macrobrachium rosenbergii during ice storage. Bull. Fac. Edu. Ibaraki Univ. (Nat. Sci.), 50: 39-49.

Rahman, M., Yasmin, L., Kamal, M., Kamruzzaman, M., Islam, M. N. and Ochiai, Y. $2001 b$. Effect of delayed icing on the quality changes in freshwater prawn Macrobrachium rosenbergii during subsequent storage. Bull. Fac. Edu. Ibaraki Univ. (Nat. Sci.), 50: 51-57.

Rahman, M., Yasmin, L., Kamal, M., Mazid, M. A. and Islam, M. N. 2001c. Effect of delayed icing on the quality changes in brakish water shrimp Penaeus monodon during ice storage. Pukl. Jour. Biol. Sci., 4(11): 1390-1394.

Reilly, A., Bernate, M. A. and Dangla, E. 1985. Quality changes in brakish water prawns (Penaeus monodon) during storage at ambient temperature, in ice and after delays icing. In Reilly, A. (ed). Spoilage of Tropical Fish and Product Development. FAO Fishery Report 317 Suppl., 474 p. 